Article

\title{
Artificial Intelligence and Reflections from Educational Landscape: A Review of AI Studies in Half a Century
}

\author{
Aras Bozkurt ${ }^{1,2} \mathbb{D}$, Abdulkadir Karadeniz ${ }^{1,3, *}$, David Baneres ${ }^{3,4} \mathbb{D}$, Ana Elena Guerrero-Roldán ${ }^{3,4}$ \\ and M. Elena Rodríguez ${ }^{3,4}$ (D)
}

1 Open Education Faculty, Anadolu University, 26470 Eskişehir, Turkey; arasbozkurt@gmail.com

2 College of Human Sciences, University of South Africa (UNISA), Pretoria 0003, South Africa

3 eLearn Center, Universitat Oberta de Catalunya, 08018 Barcelona, Spain; dbaneres@uoc.edu (D.B.); aguerreror@uoc.edu (A.E.G.-R.); mrodriguezgo@uoc.edu (M.E.R.)

4 Faculty of Computer Science, Multimedia and Telecommunications, Universitat Oberta de Catalunya, 08018 Barcelona, Spain

* Correspondence: akaradeniz@uoc.edu

Citation: Bozkurt, A.; Karadeniz, A.; Baneres, D.; Guerrero-Roldán, A.E.; Rodríguez, M.E. Artificial Intelligence and Reflections from Educational Landscape: A Review of AI Studies in Half a Century. Sustainability 2021, 13, 800. https://doi.org/10.3390/ su13020800

Received: 25 November 2020 Accepted: 7 January 2021 Published: 15 January 2021

Publisher's Note: MDPI stays neutral with regard to jurisdictional clai$\mathrm{ms}$ in published maps and institutional affiliations.

Copyright: (C) 2021 by the authors. Licensee MDPI, Basel, Switzerland. This article is an open access article distributed under the terms and conditions of the Creative Commons Attribution (CC BY) license (https:// creativecommons.org/licenses/by/ $4.0 /)$.

\begin{abstract}
Artificial intelligence (AI) has penetrated every layer of our lives, and education is not immune to the effects of AI. In this regard, this study examines AI studies in education in half a century (1970-2020) through a systematic review approach and benefits from social network analysis and text-mining approaches. Accordingly, the research identifies three research clusters (1) artificial intelligence, (2) pedagogical, and (3) technological issues, and suggests five broad research themes which are (1) adaptive learning and personalization of education through AI-based practices, (2) deep learning and machine Learning algorithms for online learning processes, (3) Educational human-AI interaction, (4) educational use of AI-generated data, and (5) AI in higher education. The study also highlights that ethics in AI studies is an ignored research area.
\end{abstract}

Keywords: artificial intelligence; AI; deep learning; machine learning; education; AI in education; AIEd

\section{Introduction}

Artificial Intelligence (AI) is on the rise and, knowingly or unknowingly, we communicate and interact with AI technologies. In a post humanist view, human and non-human interaction is pervasive, and it can be argued that there is a symbiotic, intertwining relationship between human and nonhuman entities. It can be further argued that the boundaries between human and non-human entities are blurring and we are moving ahead to a future where technological singularity is inevitable. It can be said that singularization has started to take place at a naive level through expert systems in many fields. Education is one of the fields that has been going through a digital transformation and it has started to take advantage of artificial intelligence and derivative technological opportunities. The current state of the art and the wide use of AI applications require us to revisit how AI is used in education to answer what we are doing presently and where we are heading to.

\subsection{A snapshot of Artificial Intelligence}

The paper entitled "Computing Machinery and Intelligence" by Turing [1] was published to propose a method for evaluating whether machines are able to think, which can be referred to as the beginning of AI. Following that, McCarthy expanded this idea and then, the field of AI has had different research lines and used different branding (e.g., machine learning, informatics, knowledge-based system, and pattern recognition) to sustain its progress at the beginning of 1980s [2]. However, these different terms evolved in time and are classified under AI, which is a generic, umbrella term that embraces past and current developments. One of the mentioned subsets is machine learning which was born from the idea of recognizing patterns and the idea that a computer or another system would 
be able to learn without coding for the specific tasks, bring a systematic view at deciding suitable algorithms could be applied to faced problems [3,4]. By the 2000s, Hinton [5] emphasized the concept of deep learning with his study entitled "Learning Multiple Layers of Representation" and argued that sensory data could be created with multilayer neural networks' connections training [6,7]. Deep learning is the development of artificial neural networks to extract from high-dimensional data [8], to discover complex structures [9] and to achieve better predictive performance [10].

Currently, deep learning, machine learning, and artificial intelligence algorithms are frequently used in the practice of the above-mentioned subjects. As can be seen in Figure 1, these concepts are related to each other but differ in terms of certain features.

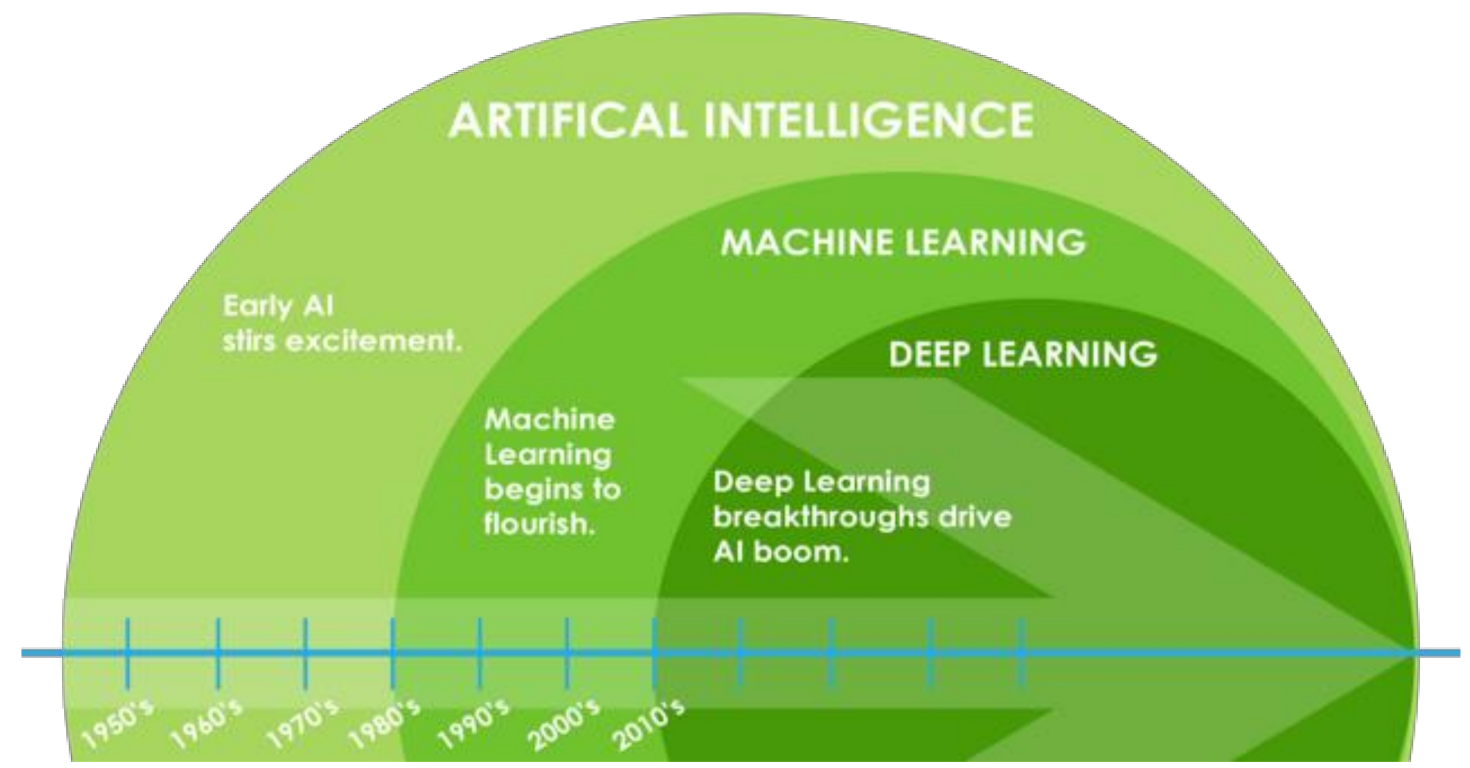

Figure 1. The relation between Artificial Intelligence, Machine Learning and Deep Learning [11].

According to Hurley [4], research that has been conducted on AI is specialized and highly technical due to programming the computing power for a certain trait including the ability to learn, plan, suggest, solve problems and most importantly to reason. In line with these developments, the beginning of the new millennium highlights an impressive process of growth, maturation, and evolution of artificial intelligence in education (AIEd) [12]. As such, AI has already been utilized in predicting students' achievement [13], identifying atrisk students in earlier stages [14,15], determining the main factors that will affect students' performance [16], conducting performance evaluation, providing descriptive information about them and contributing to teaching process [17], creating flexible, efficient learning tools, and implementing adaptive learning techniques [18]. Additionally, AI systems can drive increased student engagement leading to improved learning outcomes, integrate technologies involving interactivity, dialogue, automated question generation, and learning analytics [19]. Apart from the above-mentioned points, AI technologies are thought to have an effect on the achievement of [20] Sustainable Development Goals (SDGs) [21] and such a view requires us to revisit the use of AI technologies in different contexts including education. By benefiting from the technologies such as AI, we can reimagine a better future where teaching and learning can shape the future of humanity and the planet [22].

\subsection{Related Literature}

With many opportunities and challenges [23-27], the Horizon Report [28] argues that "AI's ability to personalize experiences, reduce workloads, and assist with the analysis of large and complex datasets recommends it to educational applications (p. 27)". As a stand for one-size-fits-all approaches [29], AI technologies in education promise personalized and adaptive learning processes [30]. 
In contrast to high interest in $\mathrm{AI}$ and its applications, there is a limited number of review studies that explore the use of AI in education. For instance, in a bibliometric study, Hinojo-Lucena, Aznar-Díaz, Cáceres-Reche and Romero-Rodríguez [31] highlighted that there is a need for more research-based, empirical findings to understand the potentials of AI in higher education. In their review study, Yang and Zhang [32] examined AI in intelligent tutoring systems and reported that factors such as learning performance, knowledge level, behaviors in the learning path, learning preferences, learning style, cognitive factors, emotional factors, cultural factors and intelligent levels can be used for delivering the adaptive learning. Roll and Wylie [12] conducted a review study to identify the foci and typical scenarios that occupy the field of AIED. They suggested that "two parallel strands of research that need to take place in order to impact education in the next 25 years: One is an evolutionary process, focusing on current classroom practices, collaborating with teachers, and diversifying technologies and domains. The other is a revolutionary process where we argue for embedding our technologies within students' everyday lives, supporting their cultures, practices, goals, and communities"' (p. 582). Zawacki-Richter, Marín, Bond and Gouverneur [33] investigated research on AI in higher education and they critically draw attention to most of the papers' "lack of critical reflection of challenges and risks of AIEd, the weak connection to theoretical pedagogical perspectives, and the need for further exploration of ethical and educational approaches in the application of AIEd in higher education." In their review study, Goksel and Bozkurt [34] identified three broad themes, namely, adaptive learning, personalization and learning styles, expert systems and intelligent tutoring systems, and AI as a future component of educational processes. However, they further noted that though AI in education has great potential, it would be misleading to accept it superior by default and researchers "need to develop a critical stance before fully integrating AI into educational processes. As part of this critical stance, first, there is a need to develop an ethical policy and to clearly define the ethical boundaries of how AI would use human-generated data. Secondly, [researchers] should test, and retest AI featured educational processes to avert automated processes and mechanical learning (p. 232)." In sum, the above studies have some common arguments: First, the use of AI and AI research is on the rise especially in the second decade of the 2000s. Second, it seems that AI has great potential if it is integrated into the educational process by benefiting from theoretical and pedagogical lenses. Third and finally, despite all its promises, there are some critical issues to be resolved before fully integrating AI into education such as ethical codes and policy on the use of AI-generated data.

With this expectation to better understand and explore the research on AI in education, this study aims to systematically address the studies focused on the use of artificial intelligence in educational environments and to demonstrate what the trend is and how it will be shaped by revealing a structured view.

\subsection{Purpose of the Research}

The main purpose of the study is to identify research trends and patterns of AI in education publications. In this context, the study seeks for the following research questions.

- What are the trends in time, subject areas and geographical distribution of AI in education publications?

- What are the patterns in textual data of AI in education publications?

\section{Materials and Methods}

\subsection{Research Design}

This study uses a systematic review approach [35] and benefits from social network analysis [36] and text-mining approaches [37]. Employing different analytical approaches enables data to be triangulated [38], strengthens interpretations through multiple perspectives, and increases the reliability and validity of the research. 


\subsection{Sample and Inclusion Criteria}

The research corpus of this study consists of 276 publications (144 conference papers and 132 articles). The inclusion criteria were to be indexed in the Scopus database, written in English, to have the search terms in their titles. The rationale to include papers with search terms only in the titles was to build a research corpus that has a certain focus on $\mathrm{AI}$ in education. Accordingly, using the search terms ("artificial intelligence" OR "AI" OR "deep learning" OR "machine learning", AND "education") in the Scopus Database, a total of 303 publications were identified and excluding publications in other languages and different publication types (Books, book chapters, editorials, etc.), the final research corpus was identified $(n=276)$.

\subsection{Analysis of Procedures}

In descriptives, frequencies and percentages were used to identify the time-trend, subject areas, and countrywide distribution. In text-mining, the large corpus of textual data was analyzed according to their lexical analysis. In the first round, only the titles of the publications were analyzed to have an initial insight and better interpret the data. This analysis yielded visual analytic outputs basing relative frequencies such as word cloud, scatter plot, trend graphic, and steam graph. In the second round, titles and abstracts were analyzed according to their lexical relationships by modifying textual data in the form of sentences. This analysis enabled a concept map which helped the researchers to identify research themes in AI studies. In the third and final round, keywords that were defined by the authors were analyzed using social network analysis (SNA). Each keyword is identified as a node and their relationships were identified according to their co-occurrences. In this phase, betweenness centrality (BC) and degree centrality (DC) metrics were used to identify keywords that have the ability to bridge other keywords, and, therefore, hold strategic positions in the network. For benchmarking purposes, authors report that Leximancer for text-mining analysis and NodeXL and Gephi for social network analysis were used to analyze the crawled.

\subsection{Strengths and Limitations}

The strength of this study lies in innovative analytical approaches that are used to analyze a large corpus of data which is free from human bias and, therefore, a factor that increases the reliability and validity of the research. Besides, the number of studies regarding $\mathrm{AI}$ in education is relatively few and it is considered that this study can be a base for future studies. In addition to the strengths of the study, there are some limitations that researchers acknowledged. First, while Scopus is one of the largest databases, the invaluable empirical contributions that are not indexed by Scopus is not included in the analysis. Second, because the text-mining approach functions best and identifies lexical relationships when only one target language is used, the research corpus is built with publications in English. Third, authors acknowledge that the use of different search strings (e.g., IA or IAEd) may yield different peer reviewed publications. Fourth, Scopus categorizes education and educational sciences under a broad category which is social sciences. Therefore, education and educational sciences-related papers can be assumed to be under this category. Besides, some interdisciplinary papers may have been listed in different categories. Fifth and lastly, publications in the grey literature (e.g., white papers, technical reports, etc.) can provide a complementary view, however, because such publications were not indexed by academic databases, the current study cannot present reflections from these types of publications.

\section{Results}

\subsection{Descriptives}

\subsubsection{Time Trend}

Time trend analysis dates back to the mid-1970s (Figure 2) and from 1976 to 2019, it almost covers half a century. While this is not surprising, it reminds us of the AI research 
in education has different generations and has a relatively long history. The number of publications remains steady until the early 2000s and slightly increases until the middle of the second decade of 2000. By 2018 and 2019, there is a sharp increase in the number of publications, and it reaches to its peak in our corpus by 2019. The time trend analysis indicates that the $\mathrm{AI}$ in education-related publications will keep their increasing momentum. There are probably some factors reasoning for this increasing trend, especially at the end of the second decade of 2000. The capacity increase in technology, computing infrastructures, heavy investments on AI and algorithms, and other innovative developments such as highly capable central processing units, cloud computing, and demands from sectors integrating industry 4.0 can be listed as significant factors.

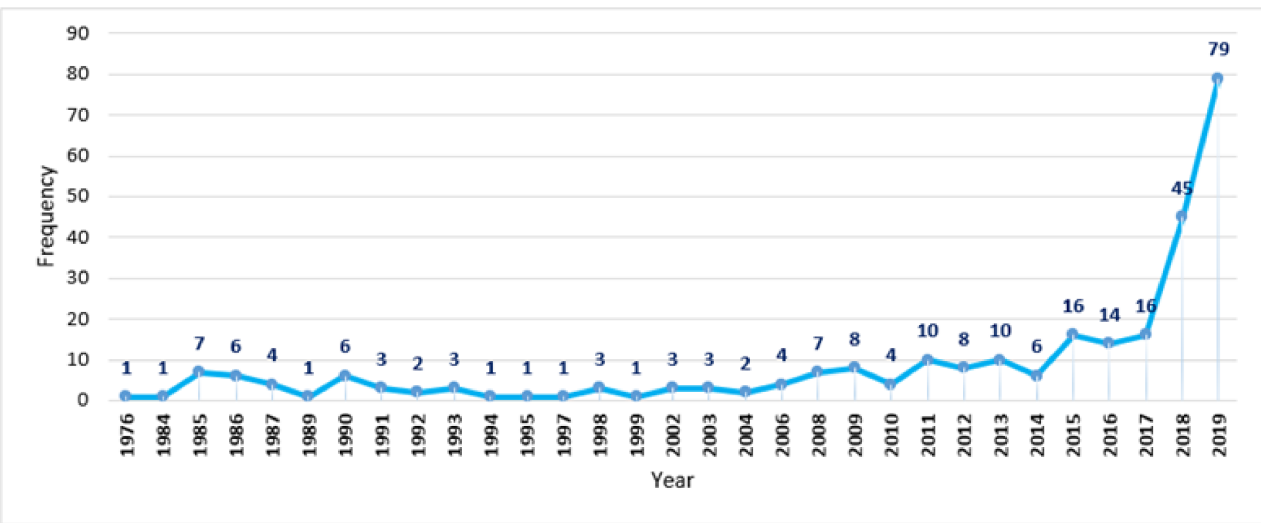

Figure 2. Time trend of the publications on Artificial Intelligence (AI) in education.

\subsubsection{Subject Areas}

Examination of subject areas, which were defined by the Scopus, demonstrates the expected findings. Accordingly, computer science (33\%), social sciences $(21 \%)$, engineering $(14 \%)$, and mathematics $(10 \%)$ contribute more than half of the total contributions. Assuming that computer science, engineering and mathematics are among the essential fields for AI-based applications, contributions from social sciences can be considered valuable (Figure 3).

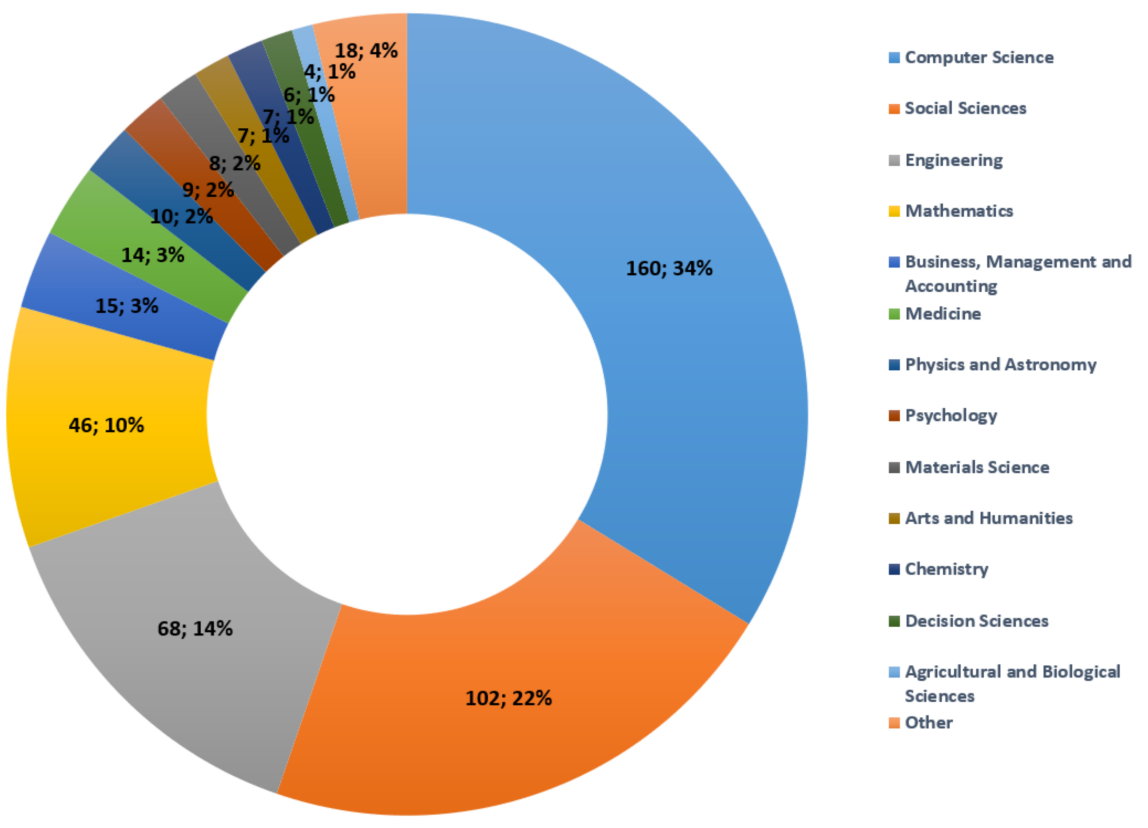

Figure 3. Distributions of the subject areas of the publications on AI in education. 


\subsubsection{Geographical Distribution}

A finely distributed number of authors from different affiliations contribute from different countries is shown in Figure 4. However, two countries, The United States (22.08\%) and China (13.96\%) seem to dominate AI in education research, which was followed by the United Kingdom (5.19\%), Australia (4.55\%), and Canada (4.22\%). Taking into account that AI research requires technological investment, expertise, and has an economic value, these countries can be regarded as innovators, or early adopters of the innovation [39]. Such a pattern means that there will be a lot of critical discussions on AI and its application in education. For instance, China has already done experimental AI practices called Smart Education in classrooms [40] and there are already rising tensions on the ethics of $\mathrm{AI}$ in education [41].

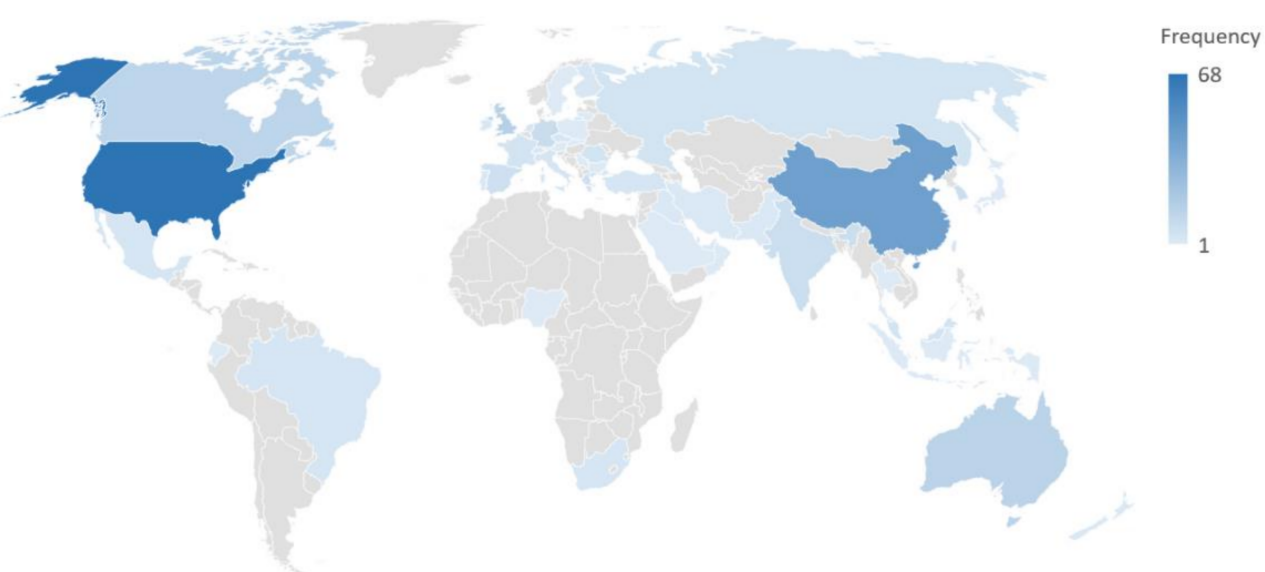

Figure 4. Geographical distributions of the publications on AI in education.

\section{2. $t$-SNE, Text-Mining and Social Network Analysis}

In order to understand the correspondence of words in the title of the publications, a non-linear technique for dimensionality reduction, t-Distributed Stochastic Neighbor Embedding (t-SNE) is used. To conduct analysis, the first 100 words were listed according to their relative frequencies and analyzed through t-SNE, which were then visualized on a scatter plot (Figure 5). The rationale to use the first 100 words with highest frequencies is to better visualize the pattern among the words with strong relationships. The analysis indicated that there are three main clusters. These are (I) artificial intelligence, (II) pedagogical, and (III) technological issues. This analysis enabled us to clearly define the borders of AI research in education. Accordingly, it can be said that AI in education is a generic technique that covers approaches such as machine learning and deep learning to predict, recognize or decide using educational data to generate smart educational processes.

The content analysis through text-mining enables researchers to explore conceptual structure data and identify the most commonly emerging themes [42]. The researchers conducted a lexical analysis of the textual data generated from titles and abstracts of the sampled articles (Figure 6). 


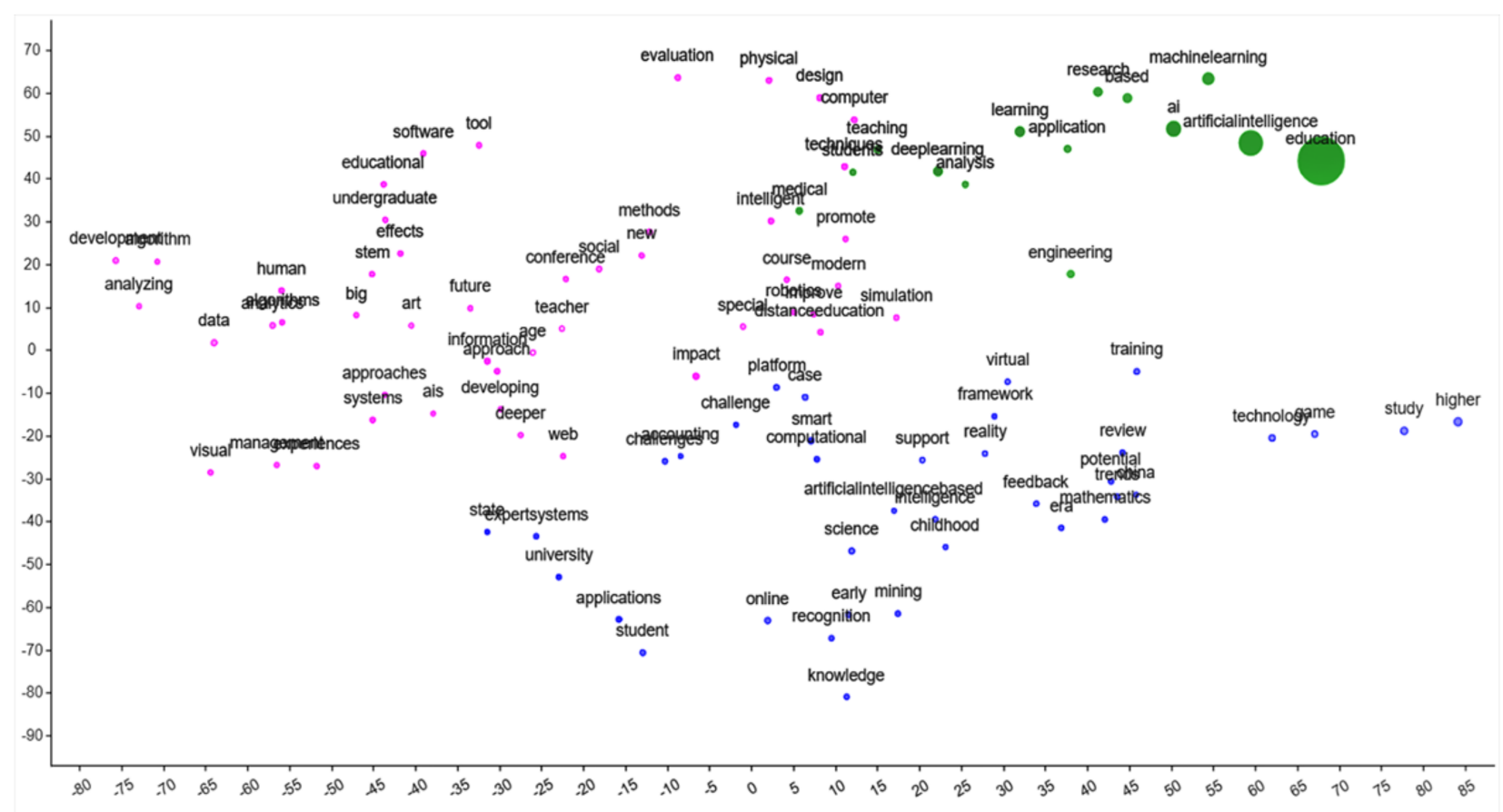

Figure 5. Scatter plot for the words appeared in the titles of the sampled publications (Larger version of the Figure 5 is presented as Appendix A).

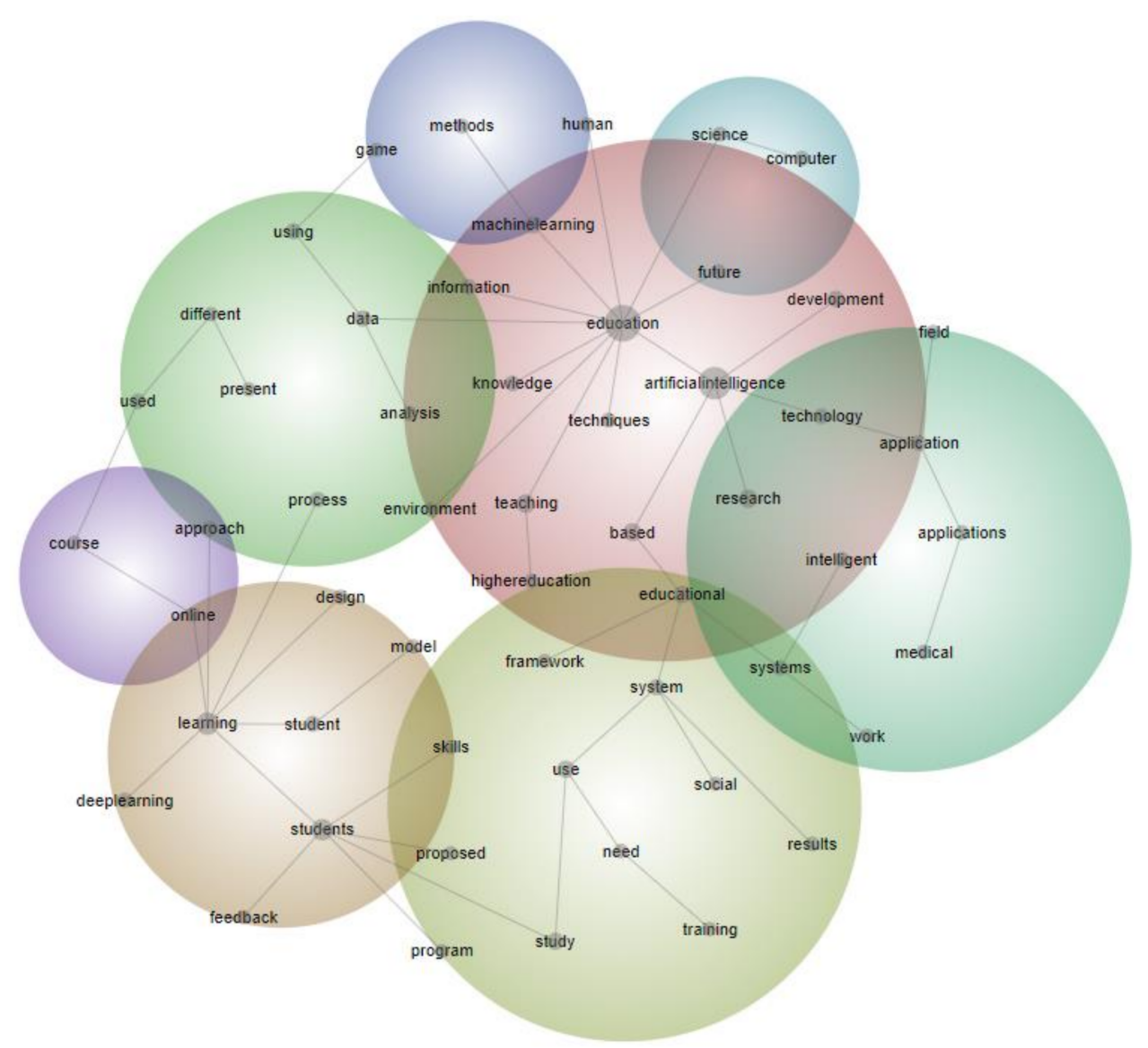

Figure 6. Concept map of $\mathrm{AI}$ in education publications. 
To triangulate data, text-mining analysis was followed by SNA, which is used to "explore and visualize patterns found within collections of linked entities" [36] (p. 32). In SNA, keywords (see Appendix B) were identified and visualized as nodes on the sociogram and their relationships were identified as arcs (Figure 7).

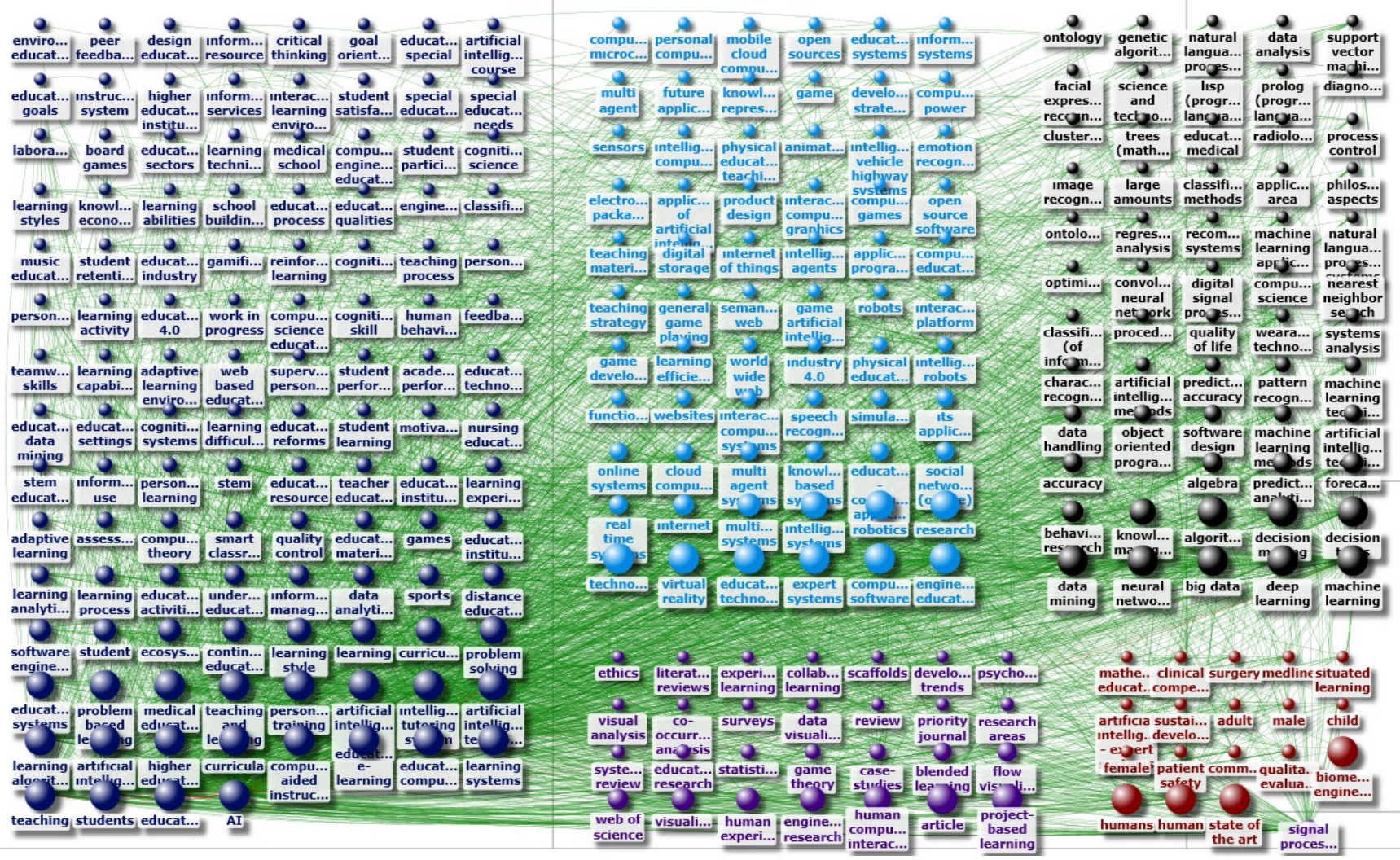

Figure 7. Sociogram of the keywords of AI in education publications (Larger version of the Figure 7 is presented as Appendix C).

The text mining and SNA assisted to identify the following themes:

Adaptive learning and personalization of education through AI-based practices (see the path in Figure 6: future, education, environment; see nodes in Figure 7: learning algorithm, intelligent tutoring systems, learning, learning style, data analytics, learning analytics, smart classroom, adaptive learning, learning experiences, personalized learning). Attributed to smart education or the Education 4.0. concept $[43,44]$, this theme indicates the possibilities to tailor and customize learning processes and create an adaptive learning environment by creating "accurate student profiles and models based upon analysis of their affective states, knowledge level, and their individual personality traits and skills" [45] (p. 47). In other words, this theme rejects the idea that "one-size fits all" [46] and highlights the importance of individual differences with an implied reference to online learning.

Deep Learning and Machine Learning algorithms for online learning processes and educational data mining (see the path in Figure 6: deep learning, learning, online, course and machine learning, education, teaching, higher education; see nodes in Figure 7: elearning, machine learning, deep learning, big data, neural networks, data mining, decision trees, decision making, algorithm). Accordingly, educational data mining is a trending issue and, in addition to many statistical approaches, deep learning and machine learning are generally used, especially for online learning [47] to profile learners and predict their behaviors to generate recommendations [48]. Triggering the developments in educational data mining and learning analytics, the use of deep learning and machine learning enabled evaluation, assessment, and monitoring of students' learning [49,50]. It was also highlighted that in addition to opportunities emerged with AI-powered learning analytics, it was also a 
solution to the need derived from interactions of learners which generated big data in the online learning at scale [51].

Educational human-AI interaction (see the path in Figure 6: human, education, artificial intelligence, technology; see nodes in Figure 7: human computer interaction, behavioral research). It is argued that human-AI interaction is a means to augment each other's abilities (e.g., Goal Augmentation, Perceptual Augmentation, Action Augmentation, and Decision Augmentation) [52]. Therefore, it is highlighted that AI "algorithms must be designed with awareness that they are part of a larger system consisting of humans" [53] (p. 33) and it is further noted that, as a result of rising machine agency [54], we need a clear set of guidelines and codes to regulate human-AI interaction [55] in an explicit and transparent manner [56].

Educational use of AI-generated data (see the path in Figure 6: using, data, education, information, artificial intelligence, based, educational, systems; see nodes in Figure 7: artificial intelligence, education, students, teaching, learning systems, computer-aided instruction, learning analytics). It is reported that use of AI-generated data through learning analytics and intelligent tutoring systems improve student performance [57]. Due to significant progress in theory and practice derived from the application of AI [12] and the potentials in educational data mining, learning analytics [50,58], it is further argued that $\mathrm{AI}$ is a future component of educational processes [34].

AI in Higher Education (see the path in Figure 6: higher education, teaching, education, artificial intelligence; see nodes in Figure 7: higher education, AI in education, teaching and learning, educational systems, curriculum). Digital transformation in higher education embraced many technologies including AI [26,59]. It is considered that AI technologies are a catalyst for Web 3.0 and online learning in higher education [60]. On the other hand, diverse thoughts and skepticism regarding the future of $\mathrm{AI}$ in higher education exist. For instance, while Zawacki-Richter, Marín, Bond, and Gouverneur [33] reported that $\mathrm{AI}$ in higher education is mostly used for profiling and prediction, assessment and evaluation, adaptive systems and personalization, and intelligent tutoring systems, they further stressed out that there is a "lack of critical reflection of the pedagogical and ethical implications as well as risks of implementing AI applications in higher education" (p. 21). In a similar manner, Bates, Cobo, Mariño, and Wheeler [61] posit that:

"The key question then is whether technology should aim to replace teachers and instructors through automation, or whether technology should be used to empower not only teachers but also learners. Above all, who should control AI in education: educators, students, computer scientists, or large corporations? These are indeed existential questions if AI does become immensely successful in reducing the costs of teaching and learning: but at what cost to us as humans? Fortunately, AI is not yet in a position to provide such a threat, but this will not always be the case" (p. 12).

While the findings identified in research can be valuable, those that could not be identified can provide valuable insights. The researchers realized that ethics, while being very important in educational research, was an ignored research area in studies covering $\mathrm{AI}$ in education.

\section{Conclusions and Suggestions}

In this paper, we have analyzed the trend of artificial intelligence on education. Interesting insights have been discovered by using a combination of descriptive statistics, t-SNE, SNA, and text mining. We observed an increment of publications during recent years and this trend will probably continue during the coming years with the increment of the interest of the application of AIEd. The impact depending on the subject area unsurprisingly came from computer science fields since AIEd requires technology in order to be developed. In the forthcoming years, interdisciplinary works will probably increase since the deployment of $\mathrm{AI}$ in educational settings cannot be conducted without the help of the experts in education and social science due to the need to design AIEd applications with cumulative knowledge of theory and practice in education. In all, it would be an illusion 
to assume that AI would be used independently by ignoring the dynamics in the field of education.

$\mathrm{t}$-SNE analysis revealed three research clusters in AIEd which are artificial intelligence, pedagogical, and technological issues. The SNA and text-mining analysis uncovers the different thematic topics currently researched on AIEd. Adaptive learning and personalization of education through AI-based practices, Deep Learning and Machine Learning algorithms for online learning processes, Educational human-AI interaction, Educational use of AI-generated data, and AI in Higher Education are the main areas of research.

While the systematic review on AIEd offers new possibilities, it also raises open questions for the application of AIEd. As aforementioned, there is a lack of literature dealing with ethics of AIEd. With a similar concern, Nye [62] warned that "ethics for data sharing are still being revised to accommodate an increasingly-connected educational world". It was further stressed that no ethical code and guidelines exist for processing educational data and this issue has persisted for years. In order to explain the emergent need for such guidelines, Mouta, Torrecilla, and Pinto [63] provided some examples: "these systems take decisions on ones' learning path, may the students, parents, and teachers meet the process through which those decisions were informed?", (there is a) lack of "explainability in terms of educational decisions, for example relating to students allowance or rejection in entering some educational institutions" or "are we giving personalised learning a chance or avoiding the personal right to boredom?" (p. 2). Thus, educational systems powered by AI, without taking into account ethical considerations, can be seen as black boxes. Referring the concept of panoptical society [64], Mouto et al. [63] ended up with the conclusion "this kind of software, besides the critics on its vocation for surveillance, may create the conditions to inhibit expression and recognition of one's feelings" (p. 2). Another problem that arises in $\mathrm{AI}$ is that data are not immune to bias [65-67]. Additionally, the AI algorithms are designed by programmers and developed by companies or governments and they can include their own agendas or biases in their development stages [26]. Such examples enforce the need to increase research on ethics and AIEd. Some works have started on ethical assessment on AIed $[68,69]$ and even the European Commission, through the High-Level Expert Group on Artificial Intelligence, recently released the Ethics Guidelines for Trustworthy AI [70]. On the other hand, future and further studies are needed in the field in order to give answers to the open questions stated above.

Author Contributions: Conceptualization, data curation, formal analysis, methodology, validation, visualization, writing-original draft, writing-reviewing \& editing, A.B.; Conceptualization, writing-original draft, writing — reviewing \& editing, project administration, funding acquisition, validation, A.K.; Writing-original draft, writing-reviewing \& editing, project administration, funding acquisition, D.B.; Writing — reviewing \& editing, funding acquisition, A.E.G.-R.; Writingreviewing \& editing, funding acquisition, M.E.R. All authors have read and agreed to the published version of the manuscript.

Funding: This study is supported by the eLearn Center at Universitat Oberta de Catalunya through the project: New Goals 2018NG001 “LIS: Learning Intelligent System”.

Institutional Review Board Statement: Not applicable.

Informed Consent Statement: Not applicable.

Data Availability Statement: The data presented in this study are available on request from the corresponding author. The data are not publicly available due to technical reasons.

Availability of Data and Materials : The datasets used and/or analysed during the current study are available from the corresponding author on reasonable request.

Conflicts of Interest: The authors declare that they have no competing interests. 


\section{Appendix A}

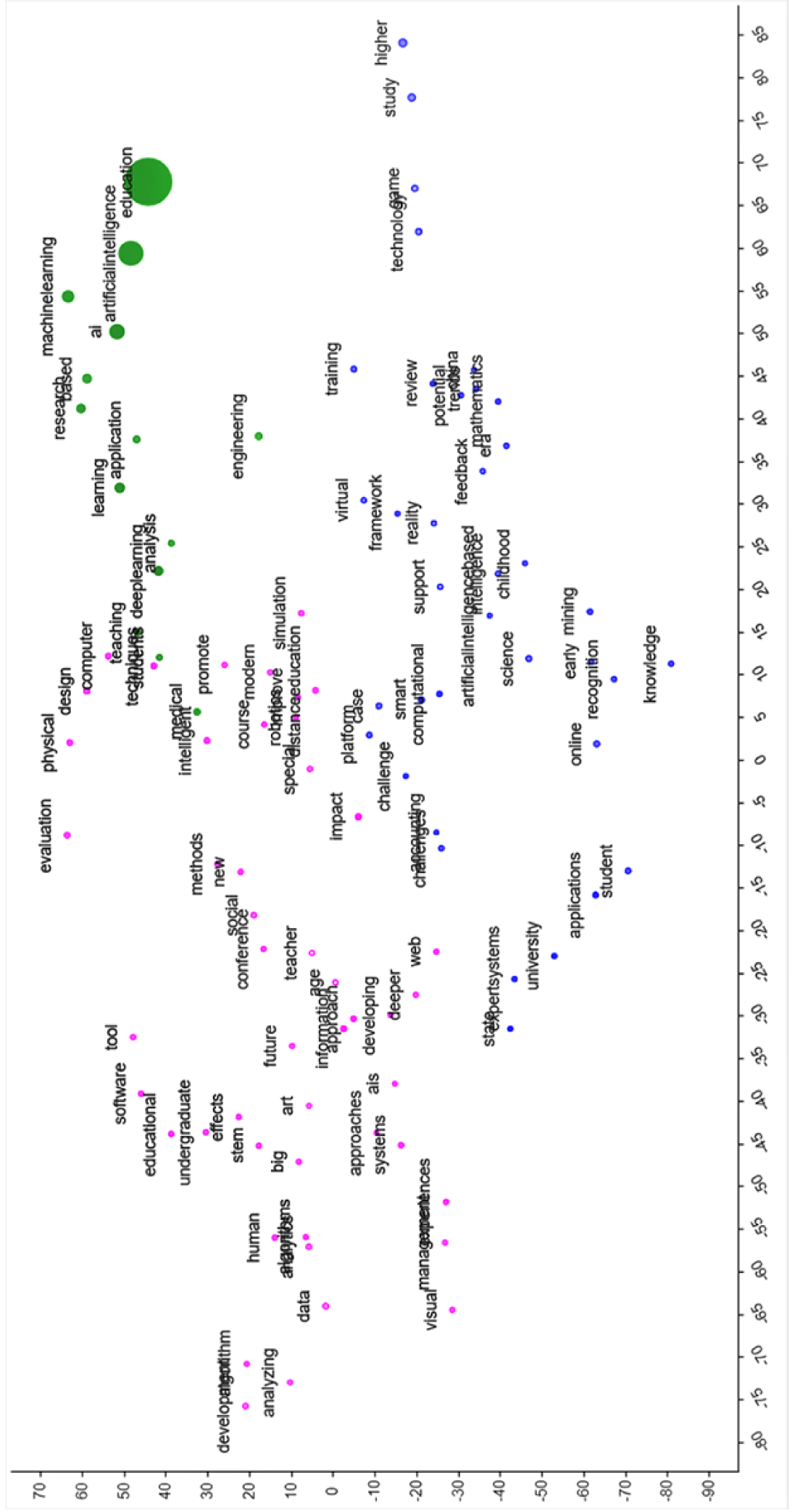

Figure A1. The larger version of Figure 5. 


\section{Appendix B}

Table A1. Top 30 keywords listed according to the highest betweenness centrality.

\begin{tabular}{|c|c|c|c|c|c|}
\hline Keywords & $D^{*}$ & $\mathbf{B C} * *$ & $\mathrm{EC} * * *$ & $\mathbf{P R} * * * *$ & $\mathrm{CC}^{* * * * *}$ \\
\hline artificial intelligence & 259 & 11110.780 & 0.020 & 9.643 & 0.089 \\
\hline education & 190 & 4591.324 & 0.016 & 6.904 & 0.120 \\
\hline students & 186 & 3377.258 & 0.017 & 6.676 & 0.130 \\
\hline teaching & 179 & 3351.602 & 0.016 & 6.444 & 0.133 \\
\hline learning systems & 176 & 3070.155 & 0.016 & 6.308 & 0.137 \\
\hline machine learning & 151 & 2155.189 & 0.015 & 5.341 & 0.160 \\
\hline engineering education & 120 & 1317.008 & 0.012 & 4.351 & 0.188 \\
\hline education computing & 114 & 1006.325 & 0.012 & 4.060 & 0.202 \\
\hline e-learning & 92 & 624.772 & 0.010 & 3.300 & 0.236 \\
\hline artificial intelligence & 82 & 614.130 & 0.008 & 2.977 & 0.220 \\
\hline deep learning & 54 & 612.181 & 0.007 & 2.104 & 0.317 \\
\hline computer software & 21 & 577.027 & 0.003 & 1.039 & 0.448 \\
\hline computer aided instruction & 87 & 542.535 & 0.009 & 3.136 & 0.242 \\
\hline curricula & 80 & 485.382 & 0.009 & 2.922 & 0.255 \\
\hline big data & 67 & 412.517 & 0.008 & 2.450 & 0.275 \\
\hline higher education & 59 & 336.804 & 0.007 & 2.190 & 0.296 \\
\hline project-based learning & 7 & 332.583 & 0.001 & 0.565 & 0.524 \\
\hline expert systems & 36 & 304.684 & 0.005 & 1.441 & 0.460 \\
\hline artificial intelligence & 3 & 289.810 & 0.000 & 0.571 & 0.000 \\
\hline learning algorithm & 66 & 266.359 & 0.008 & 2.396 & 0.332 \\
\hline state of the art & 17 & 222.444 & 0.003 & 0.798 & 0.625 \\
\hline neural networks & 59 & 215.027 & 0.008 & 2.138 & 0.338 \\
\hline educational technology & 54 & 180.560 & 0.007 & 1.966 & 0.375 \\
\hline human & 52 & 173.331 & 0.005 & 1.934 & 0.385 \\
\hline data mining & 57 & 154.360 & 0.008 & 2.033 & 0.390 \\
\hline virtual reality & 44 & 152.602 & 0.005 & 1.669 & 0.345 \\
\hline artificial intelligence technology & 44 & 145.773 & 0.005 & 1.649 & 0.341 \\
\hline intelligent tutoring system & 53 & 141.607 & 0.006 & 1.917 & 0.347 \\
\hline technology & 41 & 130.582 & 0.005 & 1.557 & 0.380 \\
\hline decision trees & 53 & 127.093 & 0.007 & 1.897 & 0.407 \\
\hline artificial intelligence in education & 40 & 125.004 & 0.005 & 1.557 & 0.347 \\
\hline
\end{tabular}




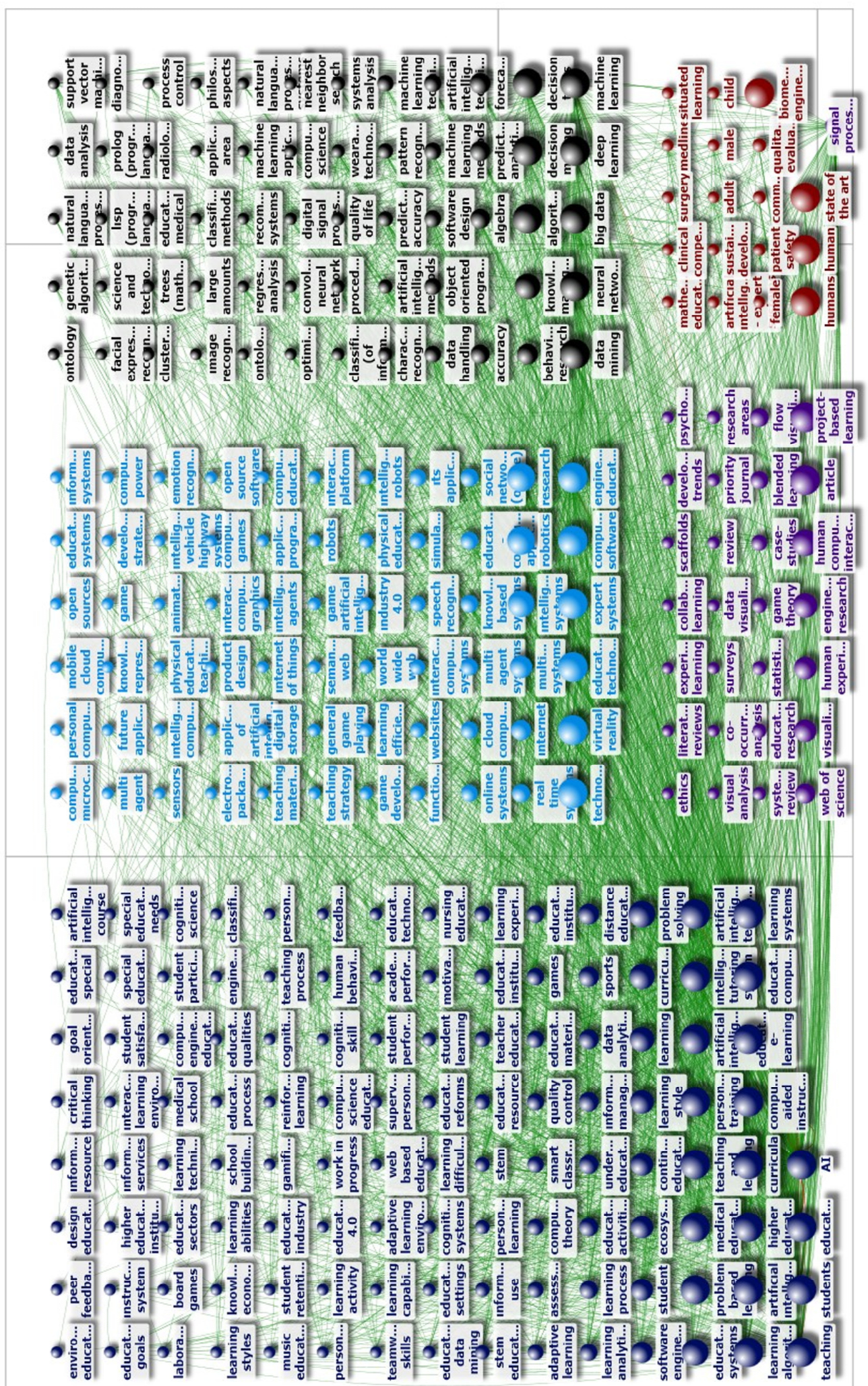

Figure A2. The larger version of Figure 7. 


\section{References}

1. Turing, A.M. Computing machinery and intelligence-AM Turing. Mind 1950, 59, 433-450. [CrossRef]

2. Anyoha, R. Can Machines Think. Science in the News, Special Edition: Artificial Intelligence, Summer. 2017. Available online: http:/ / sitn.hms.harvard.edu/flash/2017/history-artificial-intelligence/ (accessed on 9 January 2021).

3. Etzioni, O.; Banko, M.; Cafarella, M.J. Machine Reading. AAAI. 2006, Volume 6, pp. 1517-1519. Available online: https: //www.aaai.org/Papers / AAAI/2006/AAAI06-239.pdf (accessed on 9 January 2021).

4. Hurley, R. Data Science: A Comprehensive Guide to Data Science, Data Analytics, Data Mining, Artificial Intelligence, Machine Learning, and Big Data. Independently Published; 2019; ISBN 978-1704636030.

5. Hinton, G.E. Learning multiple layers of representation. Trends Cogn. Sci. 2007, 11, 428-434. [CrossRef]

6. McGuire, B.; Huang, T.; Smith, C.; Yang, G. The History of Artificial Intelligence History of Computing CSEP, 5.9.0.A; University of Washington: Seattle, WA, USA, 2006.

7. Press, G. A Very Short History of Artificial Intelligence (AI). 2016. Available online: https://www.forbes.com/sites/gilpress/20 16/12/30/a-very-short-history-of-artificial-intelligence-ai/ (accessed on 10 January 2021).

8. Chen, X.W.; Lin, X. Big data deep learning: Challenges and perspectives. IEEE Access 2014, 2, 514-525. [CrossRef]

9. LeCun, Y.; Bengio, Y.; Hinton, G. Deep learning. Nature 2015, 521, 436. [CrossRef]

10. Greenspan, H.; van Ginneken, B.; Summers, R.M. Guest editorial deep learning in medical imaging: Overview and future promise of an exciting new technique. IEEE Trans. Med Imaging 2016, 35, 1153-1159. [CrossRef]

11. Copeland, M. What's the Difference between Artificial Intelligence, Machine Learning, and Deep Learning? 2016. Available online: https:/ /blogs.nvidia.com/blog/2016/07/29/whats-difference-artificial-intelligence-machine-learning-deep-learning-ai/ (accessed on 10 January 2021).

12. Roll, I.; Wylie, R. Evolution and revolution in artificial intelligence in education. Int. J. Artif. Intell. Educ. 2016, 26, 582-599. [CrossRef]

13. Koçoğlu, F.Ö.; Emre, İ.E.; Erol, Ç.S. Observation of Success Status of Employees in E-Learning Courses in Organizations with Data Mining. Int. J. E-Adopt. 2017, 9, 38-49. [CrossRef]

14. Baneres, D.; Rodríguez-Gonzalez, M.E.; Serra, M. An early feedback prediction system for learners at-risk within a first-year higher education course. IEEE Trans. Learn. Technol. 2019, 12, 249-263. [CrossRef]

15. Minaei-Bidgoli, B.; Kashy, D.A.; Kortemeyer, G.; Punch, W.F. Predicting student performance: An application of data mining methods with an educational web-based system. In Proceedings of the 33rd Annual Frontiers in Education Conference, Westminster, CO, USA, 5-8 November 2003.

16. Al-Radaideh, Q.A.; Al-Shawakfa, E.M.; Al-Najjar, M.I. Mining student data using decision trees. In Proceedings International Arab Conference on Information Technology (ACIT'2006); Yarmouk University: Irbid, Jordan, 2006.

17. Baradwaj, B.K.; Pal, S. Mining educational data to analyze students' performance. Int. J. Adv. Comput. Sci. Appl. 2011, 2, 63-69. [CrossRef]

18. Kavitha, P.; Moorthy, B.K.; Sudharshan, P.S.; Aarthi, T. Mapping artificial intelligence and education. In 2018 International Conference on Communication, Computing and Internet of Things (IC3IoT); IEEE: Piscataway, NJ, USA, 2018; pp. 165-168. [CrossRef]

19. Kokku, R.; Sundararajan, S.; Dey, P.; Sindhgatta, R.; Nitta, S.; Sengupta, B. Augmenting Classrooms with AI for Personalized Education. Proceedings of 2018 IEEE International Conference on Acoustics, Speech and Signal Processing (ICASSP); IEEE: Piscataway, NJ, USA, 2018; pp. 6976-6980. [CrossRef]

20. Vinuesa, R.; Azizpour, H.; Leite, I.; Balaam, M.; Dignum, V.; Domisch, S.; Nerini, F.F. The role of artificial intelligence in achieving the Sustainable Development Goals. Nat. Commun. 2020, 11, 1-10. [CrossRef]

21. UN. Take Action for the Sustainable Development Goals. 2020. Available online: https://www.un.org/sustainabledevelopment/ sustainable-development-goals / (accessed on 10 January 2021).

22. UNESCO. Futures of Education: Learning to Become. 2020. Available online: https://www.un.org/sustainabledevelopment/ sustainable-development-goals / (accessed on 10 January 2021).

23. Kay, J. AI and education: Grand challenges. IEEE Intell. Syst. 2012, 27, 66-69. [CrossRef]

24. Lin, P.H.; Wooders, A.; Wang, J.T.Y.; Yuan, W.M. Artificial intelligence, the missing piece of online education? IEEE Eng. Manag. Rev. 2018, 46, 25-28. [CrossRef]

25. McCardle, J.R. The challenge of integrating ai \& smart technology in design education. Int. J. Technol. Des. Educ. 2002, 12, 59-76. [CrossRef]

26. Popenici, S.A.; Kerr, S. Exploring the impact of artificial intelligence on teaching and learning in higher education. Res. Pract. Technol. Enhanc. Learn. 2017, 12, 22. [CrossRef]

27. Sharma, R.C.; Kawachi, P.; Bozkurt, A. The landscape of artificial intelligence in open, online and distance education: Promises and concerns. Asian J. Distance Educ. 2019, 14, 1-2.

28. Educause. Educause Horizon Report 2019: Higher Education Edition. 2019. Available online: https://library.educause.edu/-/ media/files/library/2019/4/2019horizonreport.pdf (accessed on 10 January 2021).

29. Yang, S.; Tian, H.; Sun, L.; Yu, X. From One-size-fits-all Teaching to Adaptive Learning: The Crisis and Solution of Education in The Era of AI. J. Phys. 2019, 1237, 042039. [CrossRef]

30. Florea, A.M.; Radu, S. Artificial Intelligence and Education. In 2019 22nd International Conference on Control Systems and Computer Science (CSCS); IEEE: Piscataway, NJ, USA, 2019; pp. 381-382. [CrossRef] 
31. Hinojo-Lucena, F.J.; Aznar-Díaz, I.; Cáceres-Reche, M.P.; Romero-Rodríguez, J.M. Artificial intelligence in higher education: A bibliometric study on its impact in the scientific literature. Educ. Sci. 2019, 9, 51. [CrossRef]

32. Yang, J.; Zhang, B. Artificial intelligence in intelligent tutoring robots: A systematic review and design guidelines. Appl. Sci. 2019, 9, 2078. [CrossRef]

33. Zawacki-Richter, O.; Marín, V.I.; Bond, M.; Gouverneur, F. Systematic review of research on artificial intelligence applications in higher education-where are the educators? Int. J. Educ. Technol. High. Educ. 2019, 16. [CrossRef]

34. Goksel, N.; Bozkurt, A. Artificial Intelligence in Education: Current Insights and Future Perspectives. In Handbook of Research on Learning in the Age of Transhumanism Hershey; Sisman-Ugur, S., Kurubacak, G., Eds.; IGI Global: Hershey, PA, USA, 2019; pp. 224-236. [CrossRef]

35. Petticrew, M.; Roberts, H. Systematic Reviews in the Social Sciences: A Practical Guide; John Wiley \& Sons: Hoboken, NJ, USA, 2008.

36. Hansen, D.; Shneiderman, B.; Smith, M.A. Analyzing Social Media Networks with NodeXL: Insights from a Connected World; Morgan Kaufmann: Amsterdam, The Netherlands, 2010.

37. Weiss, S.M.; Indurkhya, N.; Zhang, T.; Damerau, F. Text Mining: Predictive Methods for Analyzing Unstructured Information; Springer Science \& Business Media: Berlin/Heidelberg, Germany, 2010.

38. Foster, R.L. Addressing epistemologic and practical issues in multimethod research: A procedure for conceptual triangulation. Adv. Nurs. Sci. 1997, 20, pp. 1-12. Available online: https://journals.lww.com/advancesinnursingscience/pages/default.aspx (accessed on 10 January 2021).

39. Rogers, E.M. Diffusion of Innovations; Free Press: New York, NY, USA, 2003.

40. Sheldon, N. China Has Started a Grand Experiment in AI Education. It Could Reshape How the World Learns. MIT Technology Review. 2019. Available online: https:/ / www.technologyreview.com/s/614057/china-squirrel-has-started-a-grand-experimentin-ai-education-it-could-reshape-how-the/ (accessed on 10 January 2021).

41. Wang, Y.; Hong, S.; Tai, C. China's Efforts to Lead the Way in AI Start in Its Classrooms. Wall Street J. 2019. Available online: https: //www.wsj.com/articles/chinas-efforts-to-lead-the-way-in-ai-start-in-its-classrooms-11571958181 (accessed on 10 January 2021).

42. Crofts, K.; Bisman, J. Interrogating accountability: An illustration of the use of Leximancer software for qualitative data analysis. Qual. Res. Account. Manag. 2010, 7, 180-207. [CrossRef]

43. Bajaj, R.; Sharma, V. Smart Education with artificial intelligence based determination of learning styles. Procedia Comput. Sci. 2018, 132, 834-842. [CrossRef]

44. Ciolacu, M.; Tehrani, A.F.; Binder, L.; Svasta, P.M. Education 4.0-Artificial Intelligence Assisted Higher Education: Early recognition System with Machine Learning to support Students' Success. In 2018 IEEE 24th International Symposium for Design and Technology in Electronic Packaging (SIITME); IEEE: Piscataway, NJ, USA, 2018; pp. 23-30. [CrossRef]

45. Almohammadi, A.; Hagras, H.; Alghazzawi, D.; Aldabbagh, G. A survey of artificial intelligence techniques employed for adaptive educational systems within e-learning platforms. J. Artif. Intell. Soft Comput. Res. 2017, 7, 47-64.

46. Murray, R.; Shea, M.; Shea, B.; Harlin, R. Issues in education: Avoiding the one-size-fits-all curriculum: Textsets, inquiry, and differentiating instruction. Child. Educ. 2004, 81, 33-35. [CrossRef]

47. Salloum, S.A.; Alshurideh, M.; Elnagar, A.; Shaalan, K. Mining in Educational Data: Review and Future Directions. Proceedings of Advances in Intelligent Systems and Computing; Springer International Publishing: Cham, Switzerland, 2020; pp. 92-102. [CrossRef]

48. Hernández-Blanco, A.; Herrera-Flores, B.; Tomás, D.; Navarro-Colorado, B. A systematic review of deep learning approaches to educational data mining. Complexity 2019, 2019, 1-22. [CrossRef]

49. Aldowah, H.; Al-Samarraie, H.; Fauzy, W.M. Educational data mining and learning analytics for 21st century higher education: A review and synthesis. Telemat. Inform. 2019, 37, 13-49. [CrossRef]

50. Papamitsiou, Z.; Economides, A. Learning Analytics and Educational Data Mining in Practice: A Systematic Literature Review of Empirical Evidence. Educ. Technol. Soc. 2014, 17, pp. 49-64. Available online: https://www.jstor.org/stable/jeductechsoci.17.4.49 (accessed on 10 January 2021).

51. Ray, S.; Saeed, M. Applications of educational data mining and learning analytics tools in handling big data in higher education. In Applications of Big Data Analytics; Springer: Cham, Switzerland, 2018; pp. 135-160.

52. Holstein, K.; Aleven, V.; Rummel, N. A Conceptual Framework for Human-AI Hybrid Adaptivity in Education. In International Conference on Artificial Intelligence in Education; Springer: Cham, Switzerland, 2020; pp. 240-254. [CrossRef]

53. Riedl, M.O. Human-centered artificial intelligence and machine learning. Hum. Behav. Emerg. Technol. 2019, 1, 33-36. [CrossRef]

54. Sundar, S.S. Rise of Machine Agency: A Framework for Studying the Psychology of Human-AI Interaction (HAII). J. Comput. -Mediat. Commun. 2020, 25, 74-88. [CrossRef]

55. Amershi, S.; Weld, D.; Vorvoreanu, M.; Fourney, A.; Nushi, B.; Collisson, P.; Teevan, J. Guidelines for human-AI interaction. In Proceedings of the 2019 CHI Conference on Human Factors in Computing Systems, Scotland, UK, 04-09 May 2019; pp. 1-13. [CrossRef]

56. Hois, J.; Theofanou-Fuelbier, D.; Junk, A.J. How to Achieve Explainability and Transparency in Human AI Interaction. In International Conference on Human-Computer Interaction; Springer: Cham, Switzerland, 2019; pp. 177-183.

57. Malik, M. Meta-analysis and review of the use of Artificial Intelligence and Learning Analytics within Engineering Education at University level. In 5th Symposium of the UK E IE Engineering Education Network; Royal Academy of Engineering: London, UK, 2018; pp. 38-41. 
58. Rienties, B.; Køhler Simonsen, H.; Herodotou, C. Defining the boundaries between Artificial Intelligence in Education, ComputerSupported Collaborative Learning, Educational Data Mining, and Learning Analytics: A need for coherence. Front. Educ. 2020, 2020. [CrossRef]

59. Pence, H.E. Artificial Intelligence in Higher Education: New Wine in Old Wineskins? J. Educ. Technol. Syst. 2019, 48, 5-13. [CrossRef]

60. Rubens, N.; Kaplan, D.; Okamoto, T. E-Learning 3.0: Anyone, anywhere, anytime, and AI. In International Conference on Web-based Learning; Springer: Berlin/Heidelberg, Germany, 2012; pp. 171-180.

61. Bates, T.; Cobo, C.; Mariño, O.; Wheeler, S. Can artificial intelligence transform higher education? Int. J. Educ. Technol. High. Educ. 2020, 17. [CrossRef]

62. Nye, B.D. The End of the World as We Know It: Transitioning AIED into a Service-Oriented Ecosystem. Int. J. Artif. Intell. Educ. 2016, 26, 756-770. [CrossRef]

63. Mouta, A.; Torrecilla, E.; Pinto, A. Blending machines, learning, and ethics. In Proceedings of the Seventh International Conference on Technological Ecosystems for Enhancing Multiculturality (TEEM 2019), León, Spain, 16-18 October 2019; ACM: New York, NY, USA, 2019. [CrossRef]

64. Bozkurt, A.; Sharma, R.C. Education in normal, new normal, and next normal: Observations from the past, insights from the present and projections for the future. Asian J. Distance Educ. 2020, 15, i-x. [CrossRef]

65. Murphy, R.F. Artificial Intelligence Applications to Support K-1 2 Teachers and Teaching; RAND Corporation: Santa Monica, CA, USA, 2019. [CrossRef]

66. Gitelman, L.; Jackson, V. Introduction. In "Raw Data" Is an Oxymoron; Gitelman, L., Ed.; The MIT Press: Cambridge, MA; London, UK, 2013; pp. 1-14. [CrossRef]

67. Nichols, M.; Holmes, W. Don't do evil: Implementing artificial intelligence in universities. Towards Pers. Guid. Support Learn. 2018, 109, 110-118.

68. Wright, D.; Finn, R.; Gellert, R.; Gutwirth, S.; Schütz, P.; Friedewald, M.; Venier, S.; Mordini, E. Ethical dilemmas scenarios and emerging technologies. Technol. Forecast. Soc. Chang. 2014, 87, 325-333. [CrossRef]

69. Brey, P. Ethics of Emerging Technologies. In Methods for the Ethics of Technology; Hansson, S.O., Ed.; Rowman and Littlefield International: Lanham, MD, USA, 2017.

70. HLEG. Ethics Guidelines for Trustworthy AI. 2019. Available online: https://ec.europa.eu/digital-single-market/en/news/ ethics-guidelines-trustworthy-ai (accessed on 23 May 2020). 